This item is the archived peer-reviewed author-version of:

Kinetic properties and heme pocket structure of two domains of the polymeric hemoglobin of Artemia in comparison with the native molecule

\title{
Reference:
}

Akbari Borhani Heshmat, Berghmans Herald, Trashin Stanislav, De Wael Karolien, Fago Angela, Moens Luc, Habibi-Rezaei Mehran, Dewilde Sylvia.- Kinetic properties and heme pocket structure of two domains of the polymeric hemoglobin of Artemia in comparison with the native molecule

Biochimica et biophysica acta : proteins and proteomics - ISSN 1570-9639 - (2015), p. 1-10

DOI: http://dx.doi.org/doi:10.1016/j.bbapap.2015.05.007 


\section{Q3 Kinetic properties and heme pocket structure of two domains of the polymeric hemoglobin of Artemia in comparison with the native molecule}

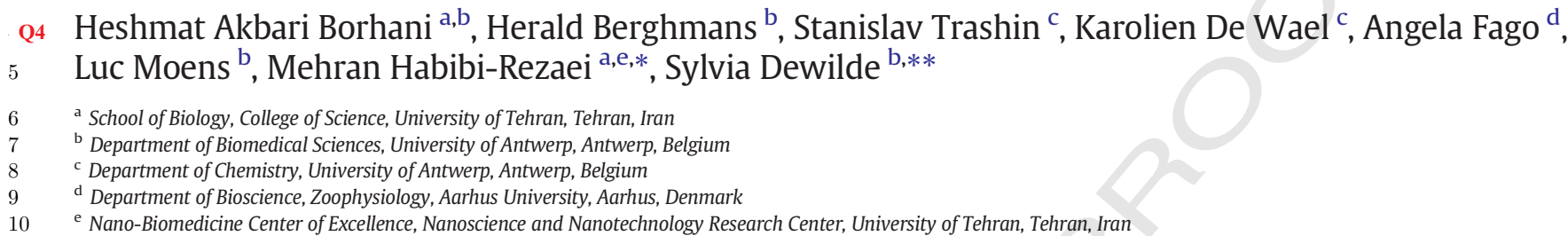

\section{A R T I C L E I N F O}

\section{Article history:}

Received 6 February 2015

Received in revised form 30 April 2015

Accepted 14 May 2015

Available online xxxx

\section{Keywords:}

Artemia hemoglobin

Ligand binding kinetics

Heme pocket structure

Redox potential

\begin{abstract}
A B S T R A C T
In this project, we studied some physicochemical properties of two different globin domains of the polymeric he- 22 moglobin of the brine shrimp Artemia salina and compared them with those of the native molecule. Two domains 23 (AsHbC1D1 and AsHbC1D5) were cloned and expressed in BL21(DE3)pLysS strain of Escherichia coli. The recom- Q5 binant proteins as well as the native hemoglobin $(\mathrm{AfHb})$ were purified from bacteria and frozen Artemia, respec- 25 tively by standard chromatographic methods and assessed by SDS-PAGE. The heme environment of these 26 proteins was studied by optical spectroscopy and ligand-binding kinetics (e.g. $\mathrm{CO}$ association and $\mathrm{O}_{2}$ binding af- 27 finity) were measured for the two recombinant proteins and the native hemoglobin. This indicates that the CO 28 association rate for $A s \mathrm{HbC1D} 1$ is higher than that of $A s \mathrm{HbC1D} 5 \mathrm{and} A f \mathrm{Hb}$, while the calculated $P_{50}$ value for 29 AsHbC1D1 is lower than that of AsHbC1D5 and AfHb. The geminate and bimolecular rebinding parameters indi- 30 cate a significant difference between both domains. Moreover, EPR results showed that the heme pocket in AfHb 31 is in a more closed conformation than the heme pocket in myoglobin. Finally, the reduction potential of $-0.13 \mathrm{~V} 32$ versus the standard hydrogen electrode was determined for $A f \mathrm{Hb}$ by direct electrochemical measurements. It is 33 about $0.06 \mathrm{~V}$ higher than the potential of the single domain AsHbC1D5. This work shows that each domain in the 34 hemoglobin of Artemia has different characteristics of ligand binding.
\end{abstract}

(c) 2015 Published by Elsevier B.V.

\section{Introduction}

Hemoglobins (Hbs) are a specific class of proteins consisting of a single or multiple globin chains. These globin chains display the specific globin fold consisting of 7 or $8 \alpha$-helical segments (indicated A to $\mathrm{H})$ wrapped around a heme b moiety according to a 3-over-3 $\alpha$ helical sandwich pattern $[1,2]$. The heme iron atom is penta- (F8His) or hexa-coordinate depending on the presence of an internal 6th ligand (usually E7His) [3,4]. Comparative studies demonstrate that Hbs occur in all kingdoms of life and that the canonical globin fold displays an

* Correspondence to: M. Habibi-Rezaei, School of Biology, College of Science, University of Tehran, Tehran, Iran. Tel.: +98 21611132 14; fax: +982166 492992.

** Correspondence to: S. Dewilde, University of Antwerp, Universiteitsplein 1, 2610 Wilrijk, Belgium. Tel.: + 32326523 23; fax: + 3232652248 .

E-mail addresses: heshmat.akbariborhani@uantwerpen.be (H.A. Borhani), herald.berghmans@uantwerpen.be (H. Berghmans), stanislav.trashin@uanwerpen.be (S. Trashin), karolien.dewael@uantwerpen.be (K. De Wael), angela.fago@biology.au.dk (A. Fago), luc.moens@uantwerpen.be (L. Moens), mhabibi@ut.ac.ir (M. Habibi-Rezaei), sylvia.dewilde@uantwerpen.be (S. Dewilde). extreme flexibility [4-7]. Due to the reactivity of the heme iron atom, 50 globins are involved in a diversity of reactions varying e.g. from $\mathrm{O}_{2}$ me- 51 tabolism $\left(\mathrm{O}_{2}\right.$ sensing, carrying, storing) to redox chemistry (nitroso and 52 oxidative stress metabolism) [8]. In some invertebrate classes (Annelida, 53 Mollusca, Crustacea), Hbs occur as high $\mathrm{M}_{\mathrm{r}}$ proteins dissolved in the ex- 54 tracellular fluid or hemolymph. Such high $\mathrm{M}_{\mathrm{r}}$ is necessary e.g. to avoid 55 pigment loss due to excretory filtration events. This high $\mathrm{M}_{\mathrm{r}}$ is obtained 56 either by disulfide bond based aggregation (e.g. in Annelida) or by the 57 covalently concatenation of globin domains into polymeric globin 58 chains (e.g. in Mollusca, Crustacea) [7].

An example of Hbs containing polymeric globin chains are those 60 from the brine shrimp Artemia, a small branchiopod crustacean 61 inhabiting worldwide diverse ponds with variations in $\mathrm{O}_{2}$ partial pres- 62 sure due to difference in salinity (e.g. up to $50 \%$ salinity) [9]. Artemia ex- 63 presses genotypically four different globin chains $\left(\mathrm{M}_{\mathrm{r}} \sim 160,000\right)$ Q6 namely C1, C2, T1 and T2 [10-12]. Structural analyses demonstrate 65 that the $\mathrm{T}$ and $\mathrm{C}$ chains are ring-shaped polymers of nine genuine globin 66 domains covalently joined by short inter-domain linkers (Fig. 1) [13]. 67 All domains show different primary structures (identities: 23-39\%) 68 


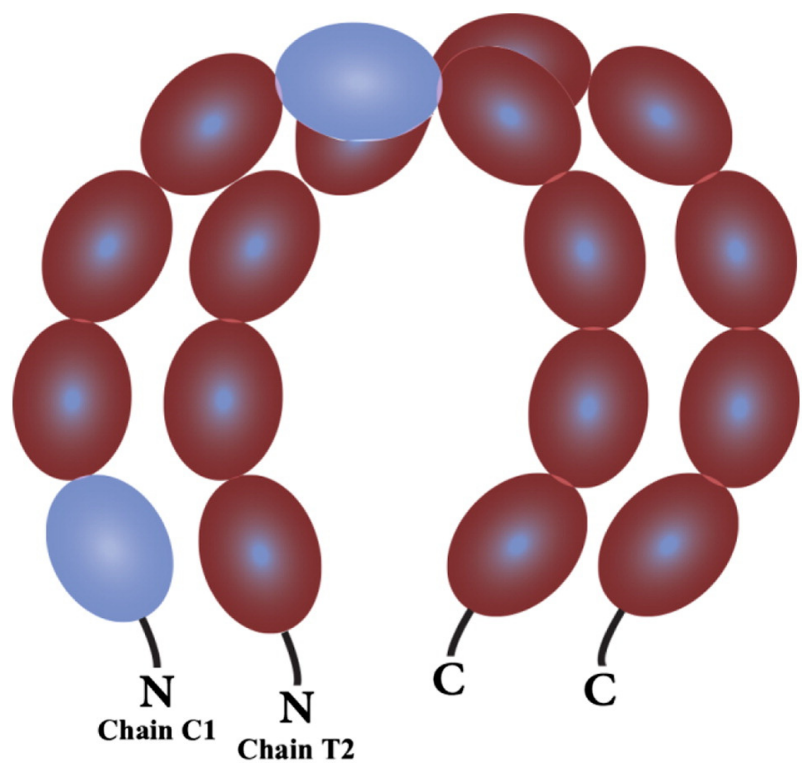

Fig. 1. Schematic view of AsHbII. AsHbC1D1 and AsHbC1D5 are presented in blue.

and are presumed to be copied originally from a single-domain gene $[11,14]$. Phenotypically, two of these ring-shaped globin chains dimerize, by coaxially stacking, to produce three heterodimeric $\mathrm{Hb}$ isoforms $\left(\mathrm{M}_{\mathrm{r}} \sim 320,000\right): \mathrm{HbI}(\mathrm{ClC} 2), \mathrm{HbII}(\mathrm{C} 1 \mathrm{T2})$ and HbIII (T1T2) [12]. Analysis of the $\mathrm{Hb}$ quaternary structure demonstrates that in both globin chains the EF helices of all domains are in contact along the interpolymer surface, and that domain 1 of the T-polymer aligns with domain 1 of the Cpolymer. Similar EF contacts are very common in cooperative Hbs [15].

The Artemia $\mathrm{Hbs}$ are definitively involved in $\mathrm{O}_{2}$ storage/transport metabolism and serve e.g. to cope with the variable $\mathrm{O}_{2}$ tension in the environment. All three $\mathrm{Hbs}$ bind $\mathrm{O}_{2}$ cooperatively and with a different affinity [16]. Their biosynthesis is differentially controlled according to the species where they are expressed in, the ontogenetical stage and the temperature, $\mathrm{pH}$ and the $\mathrm{O}_{2}$ tension of the habitat $[10,17-20]$.

The role of the individual domains in the polymeric globin chain(s) and the native $\mathrm{Hb}(\mathrm{s})$ is unclear. However, single or multi-domain fragments of Artemia salina (AsHbII), obtained by limited proteolysis, bind $\mathrm{O}_{2}$ non-cooperatively [21,22].

This paper aims to answer the following questions; firstly, whether the eighteen domains have the same role in the ligand binding or not; secondly, whether the general structure of the heme pocket in the native $\mathrm{Hb}$ of Artemia is the same as that of myoglobin, and finally, whether $\mathrm{Hb}$ of Artemia, with 18 heme centers, has a higher redox potential than the normal reference globins.

To provide an answer to these questions, we studied the physicochemical characteristics (electron paramagnetic resonance (EPR), laser-flash photolysis and redox chemistry) of two recombinant globin domains [A. salina chain C1, domains 1 (AsHbC1D1) and 5 (AsHbC1D5) (Fig. 1)] of Artemia urmiana and Artemia franciscana from Urmia salt Lake, Iran and compared them with those of native $\mathrm{Hbs}$ of A. franciscana (AfHb).

\section{Materials and methods}

\subsection{Purification of A. franciscana $\mathrm{Hbs}(\mathrm{AfH} H \mathrm{~b})$}

Native A. franciscana $\mathrm{Hbs}$ were purified from frozen material (a gift from the Laboratory of Aquaculture and Artemia Reference Center, University of Ghent, Belgium) mainly as described previously [23]. Shortly, crude $\mathrm{AfHb}$ (50\% ammonium sulfate precipitate) was further purified on a HiTrap DEAE column by step elution at $225 \mathrm{mM} \mathrm{NaCl}$. Hb tracing was spectrophotometric at $412 \mathrm{~nm}$.

\subsection{RNA extraction and amplification}

A. urmiana and A. franciscana were collected from Urmia Salt Lake, 109 Urmia, Iran. Total RNA was prepared using the combination of TriZol 110 method and PureLink RNA Mini Kit. cDNA was synthesized as described 111 elsewhere [24]. The cDNA fragments encoding globin domains 1112 (AsHbC1D1) and 5 (AsHbC1D5) of chain C1 were amplified by PCR [25]. 113

\subsection{Cloning, expression, and purification of recombinant proteins}

114

The PCR products were cloned into the TOPO-TA vector (Invitrogen) 115 followed by subcloning into pET23a vector. AsHbC1D1 and AsHbC1D5 116 were expressed in Escherichia coli strain BL21(DE3)pLysS. Cells were 117 grown at $37{ }^{\circ} \mathrm{C}$ in Terrific Broth (TB) medium (1.2\% bactotryptone, 118 $2.4 \%$ yeast extract, $0.4 \%$ glycerol, $72 \mathrm{mM}$ potassium phosphate buffer, 119 pH 7.5) containing $200 \mu \mathrm{g} / \mathrm{ml}$ ampicillin, $30 \mu \mathrm{g} / \mathrm{ml}$ chloramphenicol, 120 and $2.5 \mathrm{mM} \delta$-amino-levulinic acid. The culture was induced at 121 $A_{550}=1.2$ by the addition of isopropyl-1-thio- $\beta$-D-galactopyranoside 122 (IPTG) to a final concentration of $0.4 \mathrm{mM}$, and expression was continued 123 overnight (at $25^{\circ} \mathrm{C}$ ). The cells were harvested and resuspended in lysis 124 buffer, $50 \mathrm{mM}$ Tris- $\mathrm{HCl}$ (pH 7.5) containing $300 \mathrm{mM} \mathrm{NaCl}$.

125

The cells were exposed to three freeze-thaw steps and sonication till 126 completely lysed. The lysate was clarified by low speed (10 min at 127 $10,000 \times g$ ) centrifugation. Then, imidazole was added (final buffer 128 composition of $50 \mathrm{mM}$ Tris- $\mathrm{HCl}$ pH 7.5, $300 \mathrm{mM} \mathrm{NaCl}$, and $20 \mathrm{mM}$ imid- 129 azole) and the extract loaded on a Ni-affinity His 60 super flow column 130 (Clontech), equilibrated with the same buffer. After washing of the un- 131 bound material, the His-tagged recombinant protein was eluted by 132 $50 \mathrm{mM}$ Tris- $\mathrm{HCl} \mathrm{pH} 7.5,300 \mathrm{mM} \mathrm{NaCl}$ and $500 \mathrm{mM}$ imidazole. The frac- 133 tions containing the proteins of interest were pooled and dialyzed 134 against $50 \mathrm{mM}$ Tris- $\mathrm{HCl} \mathrm{pH} 7.5$ containing $150 \mathrm{mM} \mathrm{NaCl}$ and $0.5 \mathrm{mM} 135$ EDTA. After concentration by ultra-filtration (Amicon PM 10), the sam- 136 ples were loaded on Superdex Gf75, $15 \times 1800$ tricorn column (GE 137 Healthcare) for gel filtration chromatography. All purification steps 138 were assessed by SDS-PAGE.

\subsection{UV-visible spectroscopy}

Optical measurements were done with a Varian Cary-5 UV-visible 141 near-infrared spectrophotometer (Varian, Palo Alto, California). All 142 UV-visible spectra were measured in the range from 250 to $700 \mathrm{~nm} . \quad 143$

\subsection{Continuous wave EPR of the native protein}

X-band continuous wave (CW) EPR measurements were performed 145 on a Bruker ESP300E spectrometer with a microwave frequency of 146 $9.45 \mathrm{GHz}$ equipped with a gas-flow cryogenic system (Oxford Inc.), 147 allowing for operation from room temperature down to $2.5 \mathrm{~K}$. The mag- 148 netic field was measured with a Bruker ER035M NMR Gauss meter. Dur- 149 ing the experiments, a vacuum pump was attached to the EPR tube in 150 order to remove $\mathrm{O}_{2}$ from the frozen sample. The spectra are measured 151 with modulation amplitude of $0.8 \mathrm{mT}$, a modulation frequency of 152 $100 \mathrm{kHz}$ and a microwave power of $0.1 \mathrm{~mW}$.

For the EPR measurements, 20\% glycerol was added as a cryoprotec- 154 tant. All spectra were simulated using EasySpin, a toolbox for MATLAB 155 (Mathworks, Natick, Mass., USA).

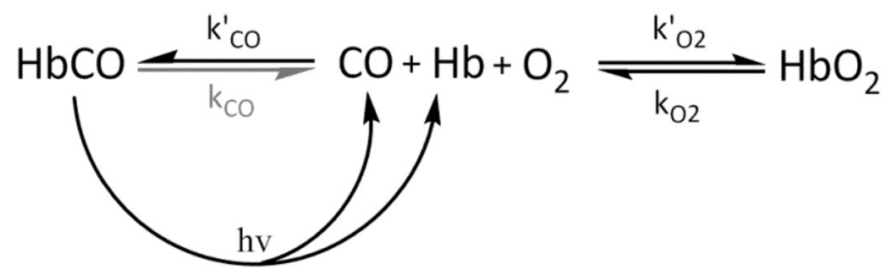




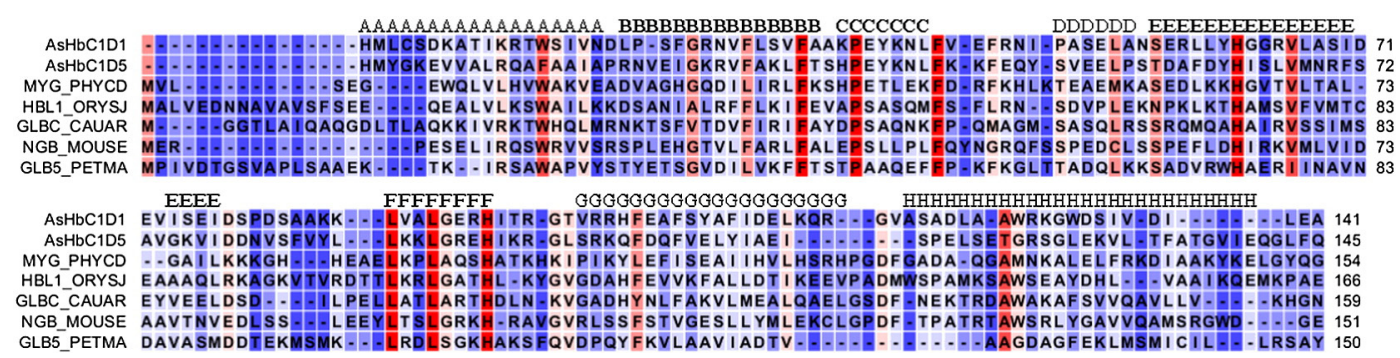

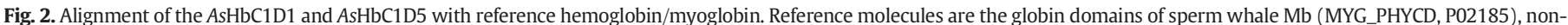

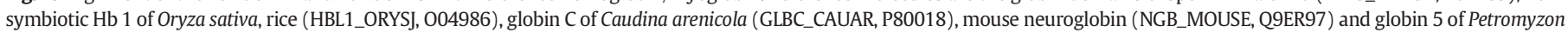
marinus (GLB5_PETMA, P02208).

\subsection{Analytical gel filtration experiments}

The apparent $\mathrm{M}_{\mathrm{r}}$ of the recombinant AsHbC1D1 and AsHbC1D5 in solution was assessed by analytical gel filtration experiments using a Superdex G27 $(2 \times 30 \mathrm{~cm}$; buffer $50 \mathrm{mM}$ Tris-HCl pH 7.5, $150 \mathrm{mM}$ $\mathrm{NaCl}$ and $0.5 \mathrm{mM}$ EDTA; $0.5 \mathrm{ml} \cdot \mathrm{min}^{-1}$ ) calibrated with human $\mathrm{Hb}$ (68 kD), cytoglobin (42 kD) and myoglobin (17 kD). Protein elution was monitored at 280 and $412 \mathrm{~nm}$. Concentration dependent oligomerization was tested by loading different $\mathrm{Hb}$ concentrations $(3.3 \mu \mathrm{M}$, $11.1 \mu \mathrm{M}, 42.5 \mu \mathrm{M}$ and $85.1 \mu \mathrm{M})$.

\section{7. $\mathrm{O}_{2}$ equilibria}

The $\mathrm{O}_{2}$ equilibrium curve for $A f H b$ was determined using a modified diffusion chamber technique described previously [26,27]. Shortly, water-saturated gaseous mixtures of $\mathrm{O}_{2}$ and ultrapure (>99.998\%) $\mathrm{N}_{2}$ created by Wösthoff (Bochum, Germany) gas mixing pumps were used to equilibrate a thin smear ( $190 \mu \mathrm{M}$ heme) of the $A f H b$ solution with different values of $\mathrm{O}_{2}$ tension $\left(P_{\mathrm{O}_{2}}\right)$. Changes in absorbance upon oxygenation were recorded continuously at $436 \mathrm{~nm}$ by a photomultiplier (model RCA 931-A, Hamamatsu, Hamamatsu city, Japan) and an Eppendorf model $1100 \mathrm{M}$ photometer (Hamburg, Germany) coupled to a potentiometric linear recorder. For reference, 0 and $100 \% \mathrm{O}_{2}$ saturation levels were obtained by equilibrating with pure $\mathrm{N}_{2}$ and $\mathrm{O}_{2}$, respectively, at the beginning and end of the experiment. $P_{50}\left(P_{\mathrm{O}_{2}}\right.$ at half-saturation) and $n_{50}$ (cooperativity) values were calculated from the zero intercept and slope, respectively, of Hill plots: $\log [\mathrm{Y} /(1-\mathrm{Y})]$ versus $\log P_{\mathrm{O}_{2}}$, where $\mathrm{Y}$ is the fractional saturation of $\mathrm{Hb}$. The curve consists of four to five saturation steps. Experiments were carried out in duplicate in $100 \mathrm{mM}$ potassium phosphate, $\mathrm{pH} 7.0$ at $20^{\circ} \mathrm{C}$.

\subsection{Ligand-binding kinetics}

2.8.1. CO binding kinetics

186

To measure the rates of $\mathrm{CO}$ association, the $\mathrm{Fe}^{3+} \mathrm{Hb}$ stock solution was 187 diluted with a $100 \mathrm{mM}$ potassium phosphate buffer, $1 \mathrm{mM}$ EDTA, pH 7.0, 188 at $20^{\circ} \mathrm{C}$ to a final concentration of $\sim 5 \mu \mathrm{M}$, equilibrated in different concen- 189 tration $(200-800 \mu \mathrm{M})$ of $\mathrm{CO}$ and anaerobically reduced with $1 \mathrm{mM}$ sodi- 190 um dithionite. The experimental setup was described in detail 191 elsewhere [28,29]. Shortly, photolysis of HbCO samples was carried out 192 on a laser photolysis system (Edinburg Instrument LP920) at $20{ }^{\circ} \mathrm{C} 193$ using the second harmonic (532 nm) of a frequency-doubled Q- 194 switched Nd:YAG laser (Spectra Physics Quanta-Ray). The absorbance 195 changes were recorded with a Tektronix TDS220 digitizing oscilloscope 196 fitted to a simple exponential expression. CO association rate value $\left(k^{\prime} 197\right.$ co) was calculated as the slope of plots of $k_{\text {obs }}$ versus [CO]. For all 198 ligand-binding kinetic studies, measurements were done at least in tripli- 199 cate and averaged.

\subsubsection{Geminate recombination}

201

The geminate rebinding time courses were fitted to one exponential 202 decay. The observed rates of geminate rebinding $\left(k_{\text {gem }}\right)$ were indepen- 203 dent of ligand concentration. The fraction of geminate recombination 204 $\left(F_{\text {gem }}\right)$ was calculated using Eq. (1):

$F_{\text {gem }}=\Delta A_{\text {gem }} / \Delta A_{\text {gem }}+y_{0}$

where $\Delta A_{\text {gem }}$ represents the absorbance change associated with the inter- 207 nal geminate rebinding and $y_{0}$ (the offset) is the difference between the absorbance after complete geminate recombination and the absorbance 208 of the original ground state, which is observed prior to the photolysis or 209 at the long times after the complete rebinding of bimolecular from the 210 solvent. As the concluded rates for CO entry and exit appeared to be the 211
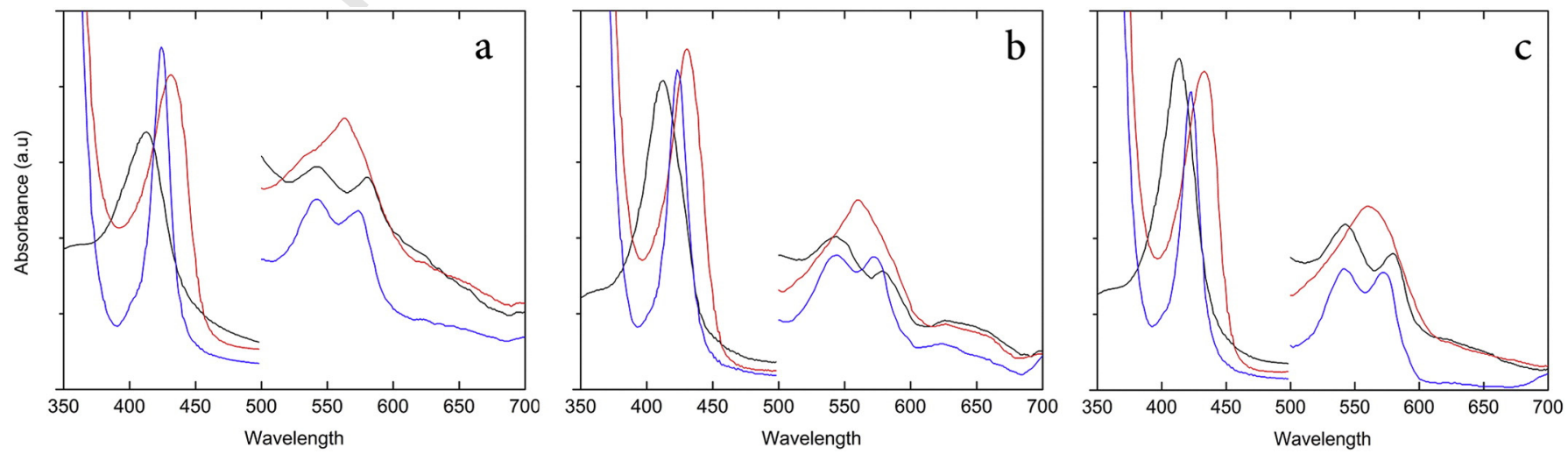

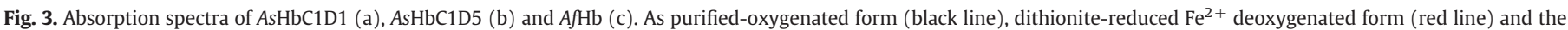
carbonylated form (blue line). 
same for those of $\mathrm{O}_{2}$ and NO due to the almost same size and polarity of three diatomic gases [30], the geminate rebinding parameters were measured for $\mathrm{CO}$.

\subsection{3. $\mathrm{O}_{2}$ binding kinetics}

Time courses for $\mathrm{O}_{2}$ association and dissociation were measured after complete laser photolysis of $\mathrm{Hb}$ samples containing various mixtures of $\mathrm{O}_{2} / \mathrm{CO}$. The mixed atmosphere allows measurement of the $\mathrm{O}_{2}$ dissociation rate. In these experiments, $\mathrm{Hb}$ samples were prepared in five different buffers with $100 \mathrm{mM}$ potassium phosphate buffer, $\mathrm{pH} \mathrm{7.0,} \mathrm{at} 20{ }^{\circ} \mathrm{C}$ containing various concentration of $\mathrm{CO}$ and $\mathrm{O}_{2}$ (e.g. $892 \mu \mathrm{M}$ of $\mathrm{CO}, 750 \mu \mathrm{M}$ of $\mathrm{CO}$ and $312.5 \mu \mathrm{M}$ of $\mathrm{O}_{2}, 500 \mu \mathrm{M}$ of $\mathrm{CO}$ and $625 \mu \mathrm{M}$ of $\mathrm{O}_{2}, 250 \mu \mathrm{M}$ of $\mathrm{CO}$ and $937.5 \mu \mathrm{M}$ of $\mathrm{O}_{2}$, and $1250 \mu \mathrm{M}$ of $\mathrm{O}_{2}$ ). The sample is essentially bound to $\mathrm{CO}$ at equilibrium because the partition coefficient between both ligands is displaced toward the $\mathrm{CO}$ form as occurs for most globins.

As shown in Scheme 1, the photolysis of HbCO by a laser beam generates a deoxyHb species which react rapidly with either ligand and two distinct phases were observed. The rate of bimolecular rebinding phase ( $k_{\text {fast }}$ ) that was dominated by $\mathrm{O}_{2}$ rebinding due to its larger association constant $\left(k^{\prime} \mathrm{O}_{2}\right)$, was monitored by a large decrease in the absorbance of unliganded $\mathrm{Hb}$ at $436 \mathrm{~nm}$ [31]. The value of $k_{\text {fast }}$ is given by Eq. (2),

$k_{\text {fast }}=k_{\mathrm{O}_{2}}^{\prime}\left[\mathrm{O}_{2}\right]+k_{\mathrm{O}_{2}}+k_{\mathrm{CO}}^{\prime}[\mathrm{CO}]$.

Generally, the CO dissociation occurs on a timescale slower compared to the $\mathrm{O}_{2}$ and then can be treated as an irreversible process.

The slow replacement phase represents the displacement of transiently bound $\mathrm{O}_{2}$ by $\mathrm{CO}$, which, although kinetically less reactive, has a higher affinity for heme. The time course of this replacement reaction is best monitored by a large increase in the difference of absorbance at $422-424 \mathrm{~nm}$. The rate of this process, $k_{\text {slow, }}$, is given by Eq. (3),

$k_{\text {slow }}=\frac{k_{\mathrm{O}_{2}}}{1+\frac{k_{\mathrm{O}_{2}}^{\prime}\left[\mathrm{O}_{2}\right]}{k_{\mathrm{CO}}^{\prime}[\mathrm{CO}]}}$

An iterative, nonlinear, least squares fitting routine (Solver in Microsoft Excel) was used to optimize the values of $k^{\prime}{ }_{\mathrm{O}_{2}}, k_{\mathrm{O}_{2}}$, and $k^{\prime} \mathrm{CO}$ to give the best fit to the dependence of $k_{\mathrm{fast}}$ and $k_{\text {slow }}$ on $\left[\mathrm{O}_{2}\right] /[\mathrm{CO}]$, including conditions of $\left[\mathrm{O}_{2}\right]=0$ and $[\mathrm{CO}] \approx 0[31]$.

\subsection{Reduction potential}

Electrochemical measurements were conducted in a conventional three-electrode cell using a $\mu$ Autolab III interface controlled by Nova 1.10 software (Metrohm-Autolab BV, Netherlands). A saturated calomel

Table 1

The absorption maxima of AsHbC1D1, AsHbC1D5 and AfHb in different forms.

\begin{tabular}{|c|c|c|c|}
\hline & Soret band (nm) & $\beta$-Band (nm) & $\alpha$-Band (nm) \\
\hline \multicolumn{4}{|c|}{ As purified oxy-form } \\
\hline AsHbC1D1 & 413 & 540 & 579 \\
\hline AsHbC1D5 & 412 & 544 & 579 \\
\hline$A f \mathrm{Hb}$ & 413 & 540 & 582 \\
\hline \multicolumn{4}{|c|}{ Reduced deoxy-form } \\
\hline AsHbC1D1 & 431 & Shoulder 528 & 562 \\
\hline AsHbC1D5 & 431 & & 559 \\
\hline$A f \mathrm{Hb}$ & 433 & & 563 \\
\hline \multicolumn{4}{|c|}{ Carbon monoxy-form } \\
\hline AsHbC1D1 & 424 & 544 & 573 \\
\hline AsHbC1D5 & 423 & 545 & 571 \\
\hline$A f \mathrm{Hb}$ & 423 & 540 & 572 \\
\hline
\end{tabular}

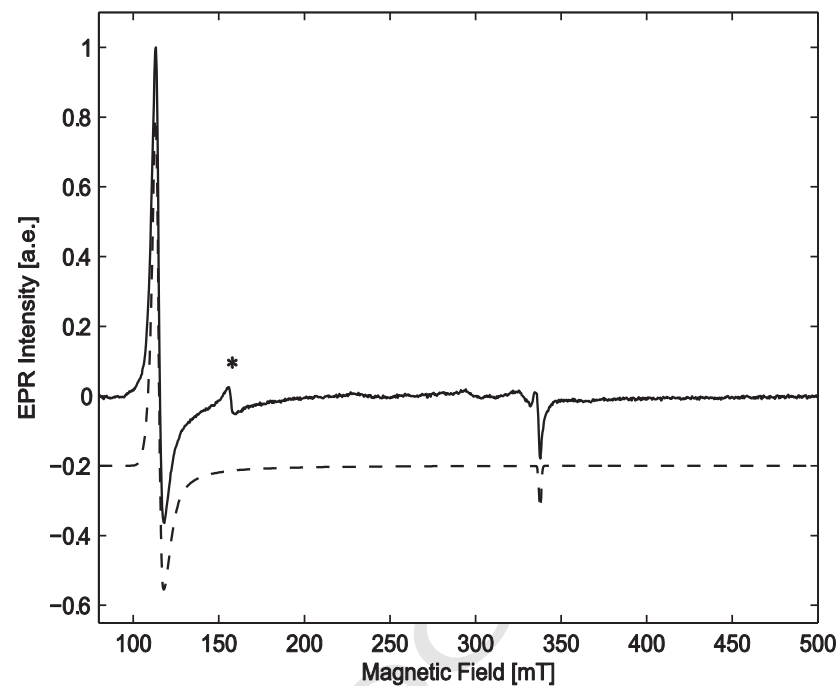

Fig. 4. X-band CW-EPR spectra of ferric native $A f H b$ (solid) and simulation (dashed). The asterisk shows the contribution to the signal of non-heme iron. All spectra were recorded at $10 \mathrm{~K}$.

electrode (SCE, $0.248 \mathrm{~V}$ versus standard hydrogen electrode (SHE) at 251 $20^{\circ} \mathrm{C}$ ) and a glassy carbon rod were used as the reference and auxiliary 252 electrodes, respectively. Prior to modification, the gold electrodes 253 ( $1.6 \mathrm{~mm}$ in diameter, BASi, USA) were polished with 1 and $0.05 \mu \mathrm{m}$ alu- 254 mina slurry, washed, and sonicated in ultrapure water for about 5 min. 255 Next, the electrodes were electrochemically cleaned by cyclic voltamm- 256 etry (CV) in $0.5 \mathrm{M} \mathrm{NaOH}$ at the potential range from -0.35 to $-1.35 \mathrm{~V} 257$ and in $0.5 \mathrm{M} \mathrm{H}_{2} \mathrm{SO}_{4}$ at the potential range from 0.2 to $1.5 \mathrm{~V}$ vs. SCE until 258 repeatable cyclic voltammograms. Then, the electrodes were incubated 259 overnight in $10 \mathrm{mM}$ 6-mercapto-1-hexanol (97\%, Sigma-Aldrich) solu- 260 tion in water. Finally, the electrodes were thoroughly washed with 261 water and dried in air stream. Electrochemistry of the proteins was 262 studied using membrane electrodes as described [32,33]. Briefly, 2- 263 $3 \mu \mathrm{l}$ of a protein solution was entrapped between the electrode and di- 264 alysis membrane (MWCO $12 \mathrm{kD}$ ). Differential pulse voltammetry 265 (DPV) was recorded before and after placing the samples on the 266 electrodes.

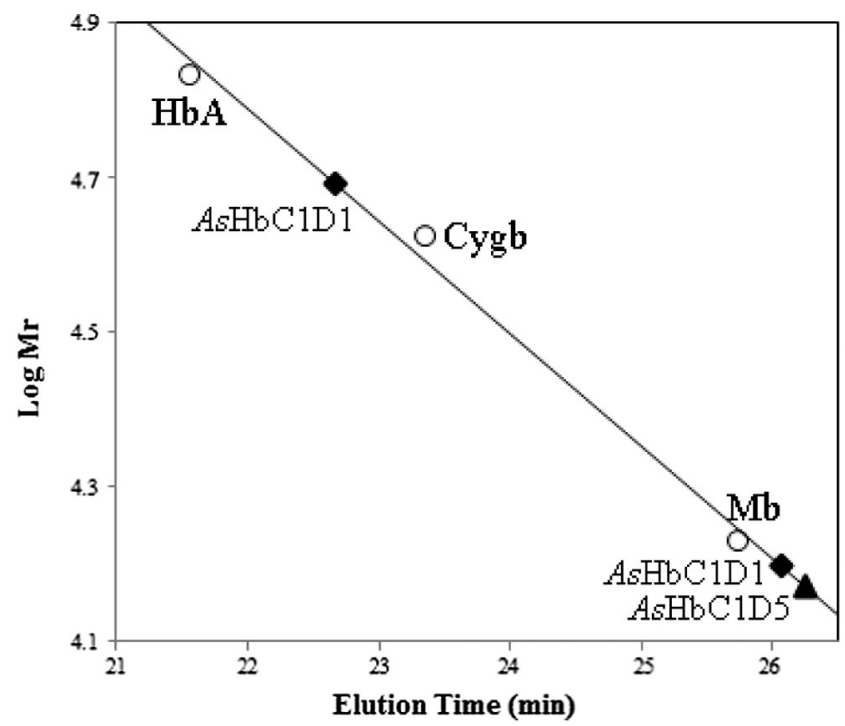

Fig. 5. Analytical gel filtration experiments. Dependence of the molecular mass on elution time; the globin standards (open circles) were human hemoglobin (HbA), human cytoglobin (Cygb), horse heart myoglobin (Mb) along with AsHbC1D1 ( $)$ and AsHbC1D5 ( $\mathbf{\Delta})$. 


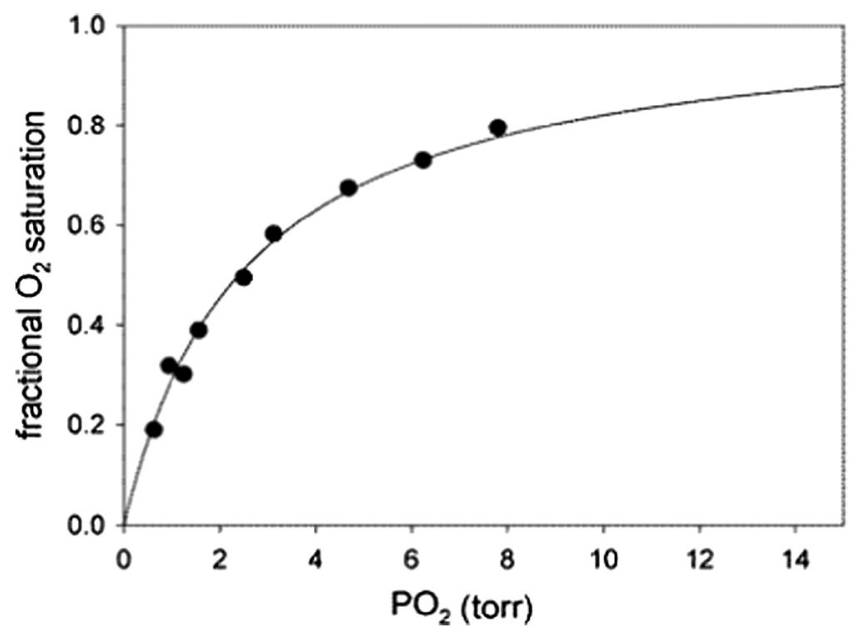

Fig. 6. Oxygen binding equilibrium curve for $A f H b$.

\section{Results}

\subsection{Cloning, expression and purification}

The obtained cDNA sequences for domains 1 and 5 from both species were compared with the reported sequence of Artemia by Manning et al. [10]. For cDNA sequences of domain 1 from $A$. urmiana and A. franciscana two differences (positions 102 and 393) and for that of domain 5 one difference (position 391) were noted. The corresponding protein sequences for both domains were exactly the same as reported in literature. Therefore, AsHbC1D1 and AsHbC1D5 were used as abbreviations to refer to the recombinant proteins of both species. AsHbC1D1 and AsHbC1D5 are composed of 141 and 145 residues, respectively. The primary structure comparison indicated $26.1 \%$ identity and $41.8 \%$ similarity between the domains. Moreover, AsHbC1D1 sequence is more similar to the non-symbiotic Hb1 of Oryza sativa, rice (38.8\%) and to the globin C of Caudina arenicola (41.0\%) whereas AsHbC1D5 is similar to the mouse neuroglobin (40.6\%) and the globin 5 of Petromyzon marinus, sea lamprey (39.1\%) (Fig. 2). Expression and purification of the recombinant AsHbC1D1 and AsHbC1D5 yielded two recombinant proteins with a molecular mass $\sim 16-17 \mathrm{kD}$, as verified by SDS-PAGE and gel filtration. The recombinant proteins were, however, not that stable and hard to store. AfHb was successfully purified from the brine shrimp and showed a molecular mass of $160 \mathrm{kD}$ by SDS-PAGE.

\subsection{UV-visible spectroscopy}

Fig. 3 shows the UV-visible absorption spectra of expressed/purified species of AsHbC1D1, AsHbC1D5 and AfHb in the oxy-, deoxy- and carbon monoxy-forms. The optical absorption spectra of the oxy-form 293 of AsHbC1D1 and AsHbC1D5 show the Soret maximum at $412 \mathrm{~nm}$ and 294 $\alpha$ and $\beta$ maxima at $579 \mathrm{~nm}$ and $540 \mathrm{~nm}$, respectively (Fig. 3, Table 1). 295 This is a typical absorbance spectrum for oxygenated globins, such as 296 sperm whale myoglobin. Moreover, the absorption spectrum of the 297 freshly purified $A f H b$ exhibits the Soret maximum at $413 \mathrm{~nm}$ and $\alpha 298$ and $\beta$ maxima at $579 \mathrm{~nm}$ and $540 \mathrm{~nm}$, respectively.

Upon CO binding to ferrous AsHbC1D1, AsHbC1D5 and AfHb, the 300 Soret maxima are shifted to 424, 423 and $423 \mathrm{~nm}$, respectively. The $\alpha 301$ and $\beta$ maxima are observed at 571-573 nm and 540-545 nm (Table 1). 302

\subsection{Continuous wave EPR of the native $\mathrm{Hb}$}

303

The EPR spectrum of ferric native AfHb is shown in Fig. 4 and indi- 304 cates that the system is in a high-spin (HS) state. In this state, the distal 305 side of the central heme iron is known to bind weak ligands like $\mathrm{H}_{2} \mathrm{O}$ or 306 have no distal ligand. Simulation of this spectrum gives the following $g-307$ values: $g_{x}=5.92, g_{y}=5.91$ and $g_{z}=1.996$. After addition of imidazole 308 (1:1 ratio imidazole:heme), which is a strong base, we expect imidazole 309 to bind to the distal side of the heme iron because of the competition 310 with the weak ligand, as is reported for metmyoglobin [34]. The EPR 311 spectrum after addition of imidazole however shows no appearance of 312 a low-spin state typical for an imidazole-ligated globin. This indicates 313 that the imidazole is not able to enter the heme-pocket, and thus native 314 AfHb has a more closed heme-pocket structure than myoglobin. $\quad 315$

\subsection{Oligomerization state analysis by gel filtration}

316

Analytical gel filtration experiments were performed to assess the 317 quaternary structure of AsHbC1D1 and AsHbC1D5 in solution (expected 318 molecular mass $=16.5$ and $17.2 \mathrm{kD}$, respectively, as calculated from se- 319 quence analysis). Elution time for AsHbC1D1 (Fig. 5) corresponds to two 320 peaks with molecular mass around $50 \mathrm{kD}$ and $16 \mathrm{kD}$, values consistent 321 with a tetramer and a monomer assembly, respectively. The elution 322 time for AsHbC1D5 correspond to a molecular mass of $15 \mathrm{kD}$, which in- 323 dicates a monomeric structure (Fig. 5). The elution times for both pro- 324 teins were the same for all tested concentrations, which indicates that 325 the oligomerization of both proteins is independent of protein 326 concentration.

\section{5. $\mathrm{O}_{2}$ equilibria}

AfHb $\mathrm{O}_{2}$ binding curve was hyperbolic (Fig. 6) with a $P_{50}$ value of 329 2.46 Torr, while the reported $P_{50}$ values for Artemia $\mathrm{Hb} \mathrm{I}, \mathrm{Hb} \mathrm{II}$ and $\mathrm{Hb} 330$ III were 5.34, 3.70 and $1.80 \mathrm{~mm} \mathrm{Hg}$, respectively [17]. Moreover, the cal- 331 culated $P_{50}$ value based on the association constant of $\mathrm{O}_{2}, \mathrm{~K}^{\mathrm{O}_{2}}$, was 332 1.51 Torr (Table 3 ). The difference can be explained by the different ex- 333 perimental conditions (e.g. pH and temperature). The native $\mathrm{Hb}$ showed 334 a cooperativity value $\left(n_{50}\right)$ close to 1.04 , which is different from the 335
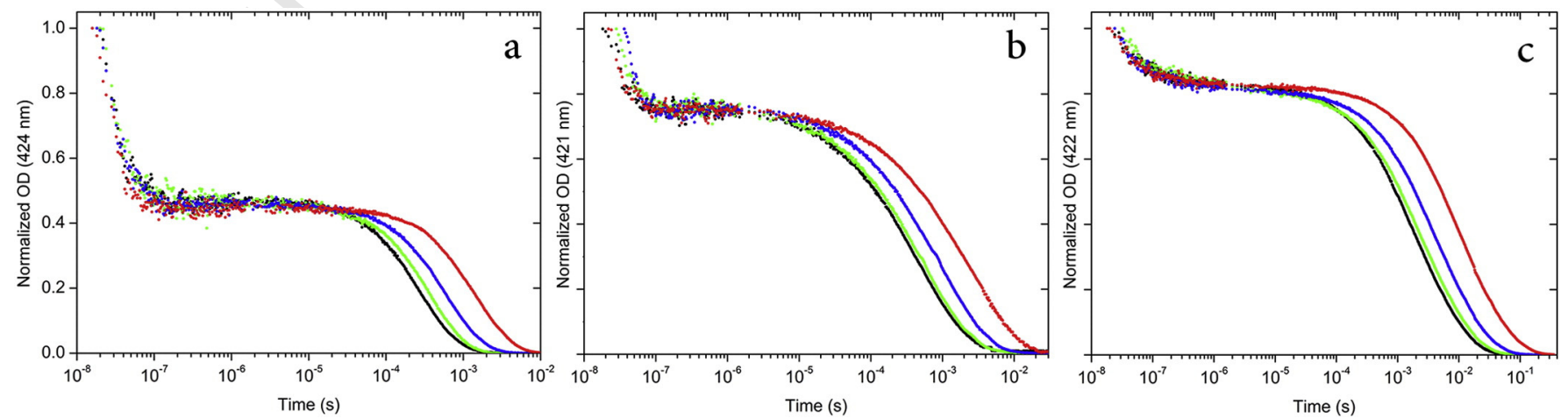

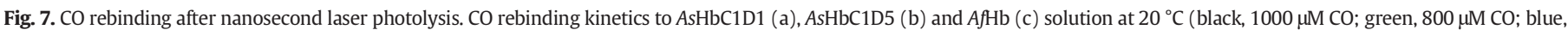
$400 \mu \mathrm{M}$ CO; red, $200 \mu \mathrm{M}$ CO). 
Table 2

Kinetic values for $\mathrm{O}_{2}$ and $\mathrm{CO}$ reactions of $\mathrm{AsHbC1D} 1$, AsHbC1D5 and $\mathrm{AfHb}$ at $\mathrm{pH} 7,20^{\circ} \mathrm{C}$ with some selected hemoglobin/myoglobin.

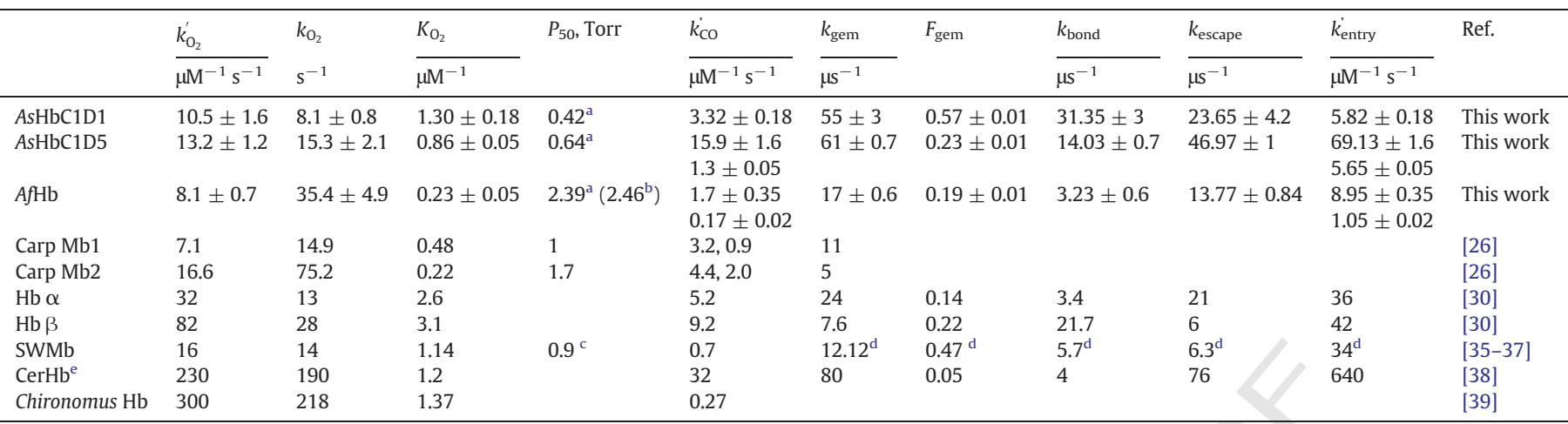

a These values are calculated based on $K_{\mathrm{O}_{2}}$ values (i.e. $P_{50}=1 /\left(1.82 * K_{\mathrm{O}_{2}}\right)$ ).

b $P_{50}$ value was measured by $\mathrm{O}_{2}$ equilibrium.

c Calculated in $22^{\circ} \mathrm{C}$.

d The kinetic values are measured based on $\mathrm{O}_{2}$ as ligand, whereas those of the recombinant proteins are measured based on $\mathrm{CO}$

e Cerebratulus lacteus mini-hemoglobin.

value of the previous report by D'Hondt study [17]. However, they reported the $n_{50}$ value for each type of Artemia's Hb.

\subsection{Ligand binding kinetics}

\subsubsection{CO association rate constant}

The $\mathrm{CO}$ association rates of AsHbC1D1, AsHbC1D5 and AfHb were measured using Laser Flash Photolysis. Fig. 7 reports the fraction of deoxy heme as a function of time after the photolysis for selected conditions. Two distinct processes in the $\mathrm{CO}$ rebinding curves are clear: i) A fast rebinding phase or geminate rebinding, which was completed in less than $2000 \mathrm{~ns}$, and shows no dependence on CO concentration; and ii) a slower phase, whose apparent rate constant depends on CO concentration, and is called bimolecular rebinding. The latter indicates the rebinding of ligands to heme iron from the solvent phase.

As shown in Fig. 7, the ligand recombination in AsHbC1D1 and AsHbC1D5 is remarkably different from each other. AsHbC1D1, showed monophasic kinetics and the extracted association rate constant is $3.32 \mu \mathrm{M}^{-1}$ (Table 2). Furthermore, AsHbC1D1 has slightly higher association rate constant than AsHbC1D5, suggesting a greater accessibility of this domain for $\mathrm{CO}$. $\mathrm{CO}$ bimolecular rebinding of both AsHbC1D5 and AfHb, however, shows biphasic kinetics that could be fitted by a double exponential relaxation. Therefore, as indicated in Table 3, the bimolecular CO association rate constants of AsHbC1D5 are 15.9 and $1.3 \mu \mathrm{M}^{-1}$, and that of $A f \mathrm{Hb}$ are 1.7 and $0.17 \mu \mathrm{M}^{-1}$. This kinetic heterogeneity for AsHbC1D5 and AfHb suggests the existence of two different conformations at equilibrium. Moreover, it is noteworthy to mention that, as there are 18 globin domains in AfHb, we cannot make a distinction between the rates of the separate domains when measuring on the native $\mathrm{Hb}$.

\subsubsection{Geminate rebinding parameters}

Internal $\mathrm{CO}$ geminate recombination was examined on nanosecond time scales to first determine the fraction of geminate recombination $\left(F_{\mathrm{gem}}\right)$ and secondly to estimate rates of internal ligand bond formation and escape. The $F_{\text {gem }}$ values of the two recombinant proteins are 0.57 and 0.23 , respectively, which indicate a different heme pocket structure or a different escape route in these proteins. The $F_{\mathrm{gem}}$ value of $A f \mathrm{Hb}$ is more close to the value of AsHbC1D5 (i.e. 0.19) (Fig. 8, Table 2).

The above mentioned kinetic features are shared with sperm whale $\mathrm{Mb}$ (SWMb) [35], although there are some small variations in the relative extent of the different phases. In particular, the fraction of geminate recombination for AsHbC1D1 (0.57) is higher than that of SWMb (0.47), whereas $F_{\text {gem }}$ of AsHbC1D5 (0.23) is lower than that of SWMb (Table 2).
However, it should be noted that the $F_{\text {gem }}$ and other kinetic values of 377 SWMb in [35] were measured based on $\mathrm{O}_{2}$ as ligand.

As shown in Fig. 8, the geminate $\mathrm{CO}$ recombination in all three sam- 379 ples appears to be a simple first order process. The $k_{\text {gem }}$ values of 380 AsHbC1D1, AsHbC1D5 are close (i.e. 55 and $61 \mu^{-1}$, respectively) 381 which is nearly 4 times greater than that of $A f H b$ (i.e. $17 \mu^{-1}$ ) (Table 2). 382

The bimolecular and geminate recombination parameters could be 383 used in calculating the internal binding and escaping rates of ligand to 384 or from the inside of the protein.

385

A two-step binding scheme was assumed for analysis that involved 386 internal bond formation between the ligand and iron atom $\left(k_{\text {bond }}\right)$ and 387 for ligand escape ( $\left.k_{\text {escape }}\right)$ from or bimolecular return $\left(k^{\prime}\right.$ entry $)$ to the 388 geminate state $(\mathrm{Hb} \cdots \mathrm{CO})$ in Scheme 2 [30]. The rate parameters which 389 fit to these processes, define the observed rates $\left(k_{\text {gem }}\right.$, Eq. (5)) and the 390 fractions $\left(F_{\mathrm{gem}}\right.$, Eq. $\left.(4)\right)$ of geminate recombination and the overall bi- 391 molecular CO association rate constant $\left(k_{\mathrm{CO}}^{\prime}\right.$, Eq. (6)) [30,40]: $\quad 392$

$$
\begin{aligned}
& F_{\text {gem }}=\frac{k_{\text {bond }}}{k_{\text {bond }}+k_{\text {escape }}} \\
& k_{\text {gem }}=k_{\text {bond }}+k_{\text {escape }} \\
& k_{\text {CO }}^{\prime}=\frac{k_{\text {entry }}^{\prime} k_{\text {bond }}}{k_{\text {escape }}+k_{\text {bond }}}=k_{\text {entry }}^{\prime} F_{\text {gem }} .
\end{aligned}
$$

The rate constant for the ligand entry, $k^{\prime}$ entry, into the individual proteins is calculated empirically as the observed bimolecular rate con- 401 stant divided by the fraction of geminate recombination $\left(k^{\prime}{ }_{\text {entry }}=k^{\prime} \mathrm{Co} / 402\right.$ $\left.F_{\text {gem }}\right)$. Therefore, $k^{\prime}$ entry is calculated independently $[30,40] . \quad 403$

The values of internal binding, ligand entry and escaping parameters 404 for studied proteins are listed in Table 3. As it is clear from Table 3, the 405 $k_{\text {bond }}$ values for AsHbC1D1, AsHbC1D5 and AfHb are 31.35, 14.03 and 406 $3.23 \mathrm{us}^{-1}$, respectively, while the $k_{\text {escape }}$ values are $23.65,46.27$ and 407 $13.77 \mu \mathrm{s}^{-1}$, respectively. It must be noted that the $k^{\prime}$ entry for AsHbC1D1 408

Table 3

\begin{tabular}{|c|c|c|c|}
\hline & Ep, reduction (V vs. SCE) & $\mathrm{E}_{1 / 2}(\mathrm{~V} \text { vs. SCE })^{\mathrm{a}}$ & $\mathrm{E}_{1 / 2}(\mathrm{~V} \text { vs. SHE })^{\mathrm{b}}$ \\
\hline AfHb & $-0.361 \pm 0.005$ & $-0.374 \pm 0.005$ & $-0.126 \pm 0.005$ \\
\hline AsHbC1D1 & $-0.399 \pm 0.005$ & $-0.412 \pm 0.005$ & $-0.164 \pm 0.005$ \\
\hline AsHbC1D5 & $-0.426 \pm 0.005$ & $-0.439 \pm 0.005$ & $-0.191 \pm 0.005$ \\
\hline
\end{tabular}

Reduction potential of $A f H b, A s H b C 1 D 1$ and AsHbC1D5 based on the differential pulse t3.2 voltammograms. 


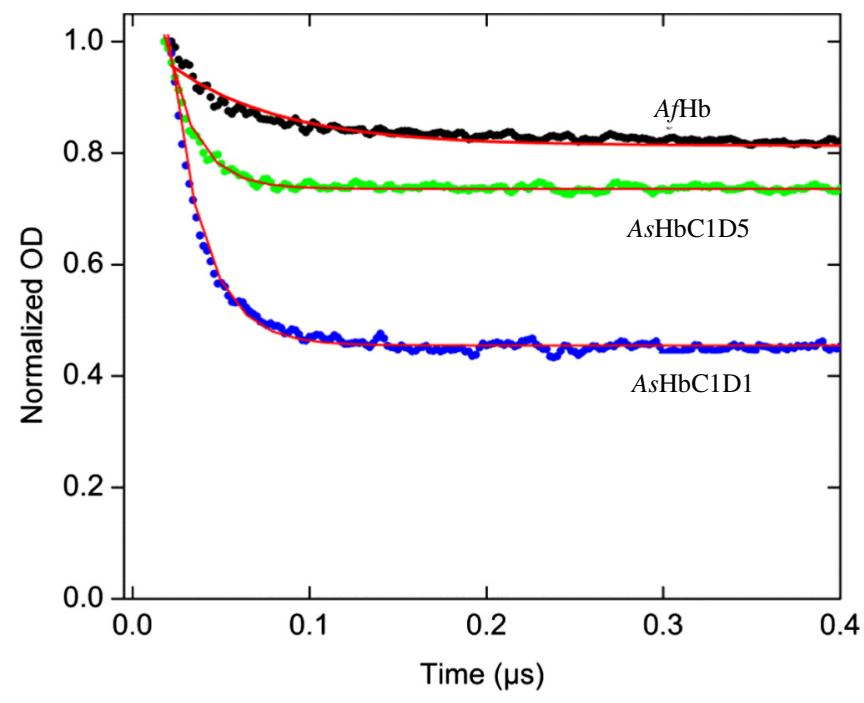

Fig. 8. Time course of CO geminate rebinding to AfHb, AsHbC1D1 and AsHbC1D5.

is $5.82 \mu \mathrm{M}^{-1} \mathrm{~s}^{-1}$, whereas this parameter for AsHbC1D5 and $\mathrm{AfHb}$ has two values (see Table 2 ).

\subsection{3. $\mathrm{O}_{2}$ association and dissociation rate constant}

Table 3 summarizes the kinetic properties of recombinant and native Artemia proteins in comparison with those of some reference $\mathrm{Hb} / \mathrm{Mb} . \mathrm{O}_{2}$ association rate constants for AsHbC1D1, AsHbC1D5 and AfHb are 10.5, 13.2 and $8.1 \mu \mathrm{M}^{-1} \mathrm{~s}^{-1}$, respectively. Although the association rate constants are very similar for all different proteins, the $\mathrm{O}_{2}$ dissociation rate constants are not. Indeed the AsHbC1D5 domain has a higher $k_{\mathrm{O}_{2}}$ $\left(15.3 \mathrm{~s}^{-1}\right)$ whereas it is even higher for $\mathrm{AfHb}\left(35.4 \mathrm{~s}^{-1}\right)$. The $\mathrm{O}_{2}$ dissociation rate constants of $A s \mathrm{HbC} 1 \mathrm{D} 5$ and $A f \mathrm{Hb}$ are respectively a factor of 2 and 4 higher, which makes the affinity for $\mathrm{O}_{2}$ for these two proteins lower.

Calculated $P_{50}$ values of AsHbC1D1 and AsHbC1D5 are 0.42 and 0.64 Torr, respectively. The calculated $P_{50}$ for the native protein is 2.39 Torr, which is very close to the measured $P_{50}$ by $\mathrm{O}_{2}$ equilibria (2.46 Torr). Therefore, the $P_{50}$ value for native $\mathrm{Hb}$ is significantly higher and $\mathrm{O}_{2}$ affinity is lower in comparison with the recombinantly expressed domains. $\mathrm{O}_{2}$ binding constant of AsHbC1D1 $\left(1.30 \mu \mathrm{M}^{-1}\right)$ is similar to Chironomus thummi thummi $\mathrm{Hb}$ [39] and the values of AsHbC1D5 $\left(0.86 \mu \mathrm{M}^{-1}\right)$ is more like to Mb2 of carp [26] (Table 2)

\subsection{Reduction potential}

Fig. 9 shows differential pulse voltammograms of the native and recombinant proteins. The redox potential is found from the peak position and differs noticeably among the proteins. As shown in Table 4, AfHb has the highest reduction potential $\mathrm{E}_{1 / 2}(-0.13 \mathrm{~V}$ versus SHE) compared to 434 AsHbC1D1 ( $-0.16 \mathrm{~V})$ and AsHbC1D5 (-0.19 V).

4. Discussion

This present study was conducted to examine the role of the differ- 437 ent domains in ligand binding of Artemia $\mathrm{Hb}$ by comparing the charac- 438 teristics of the isolated domains to the native molecule. By cloning and 439 expressing the two individual domains (AsHbC1D1: a N-terminal locat- 440 ed domain; and AsHbC1D5: an internally located domain) separately, 441 we have created one-domain, single-heme globin-like proteins, which 442 mediate ligand binding.

When comparing the C1D1 domain of $A$. franciscana and A. urmiana 444 there is no difference in the sequence at the protein level (Fig. 2) and 445 only few differences at the DNA level. The same conclusion can be 446 taken for the C1D5 domain. This suggest that strain specific sequence 447 differences are negligible.

Although there is a low identity between both recombinant domains 449 and SWMb $(\sim 25 \%)$ virtually all key hydrophobic and heme-binding res- 450 idues are conserved suggesting that both domains display the genuine 451 globin fold (Fig. 2). A first indication that confirms this, is the UV-Vis 452 spectroscopy, which shows that both recombinant domains as well as 453 the native $A f H b$, are pentacoordinated like SWMb (Fig. 3). EPR spectros- 454 copy, however, demonstrates that ferric native $A f H b$ is unable to bind 455 imidazole into the heme pocket suggesting a more closed structure 456 than seen in SWMb (Fig. 4).

The quaternary structure of both recombinant globin domains in so- 458 lution was studied by gel filtration experiments. They show that 459 AsHbC1D1 occurs predominantly as tetramer and monomer whereas 460 AsHbC1D5 occurs only as monomer. This suggests that the function of 461 both domains in the assembly of the native $\mathrm{AsHb}$ molecule is different 462 (Fig. 5). Furthermore as each globin domain separately is not stable in 463 physiological buffers, the polymeric structure is essential to stabilize 464 the Hb structure in Artemia. Hence, this confirms that the concatenation 465 of globin domains into polymeric globin chains, as mentioned by Weber 466 et al., is indispensable for stability [7].

467

The ligand binding kinetics and equilibrium studies of the native 468 AfHb and the recombinant domains C1D1 and C1D5 also indicate slight 469 differences in properties. The $P_{50}$ value of 2.46 Torr obtained by equilib- 470 rium measurements is very close to the $P_{50}$ calculated from the kinetic 471 rate constants (2.39 Torr). They are, however, different from the pub- 472 lished values (17) probably due to the fact that the $A f H b$ we used is a 473 mixture of the three $\mathrm{Hb}$ types and the difference in the experimental 474 conditions (e.g. pH and temperature) used (Fig. 6; Table 3). Calculated 475 $P_{50}$ values of $A s H b C 1 D 1$ and AsHbC1D5 were 0.42 and 0.64 Torr, respec- 476 tively. The difference in $\mathrm{O}_{2}$ affinity is due to a 1.88-fold higher $\mathrm{O}_{2}$ disso- 477 ciation rate constant $\left(k_{\mathrm{O}_{2}}\right)$ of AsHbC1D5 compared to AsHbC1D1, 478 whereas the $\mathrm{O}_{2}$ association rate constant $\left(k^{\prime} \mathrm{O}_{2}\right)$ of $A s \mathrm{HbC1D} 5$ is only 479 1.25-fold higher than AsHbC1D1 (Tables 2, 4). Furthermore, the $\mathrm{O}_{2}$ asso- 480 ciation equilibrium constant of the native protein is lower than both 481

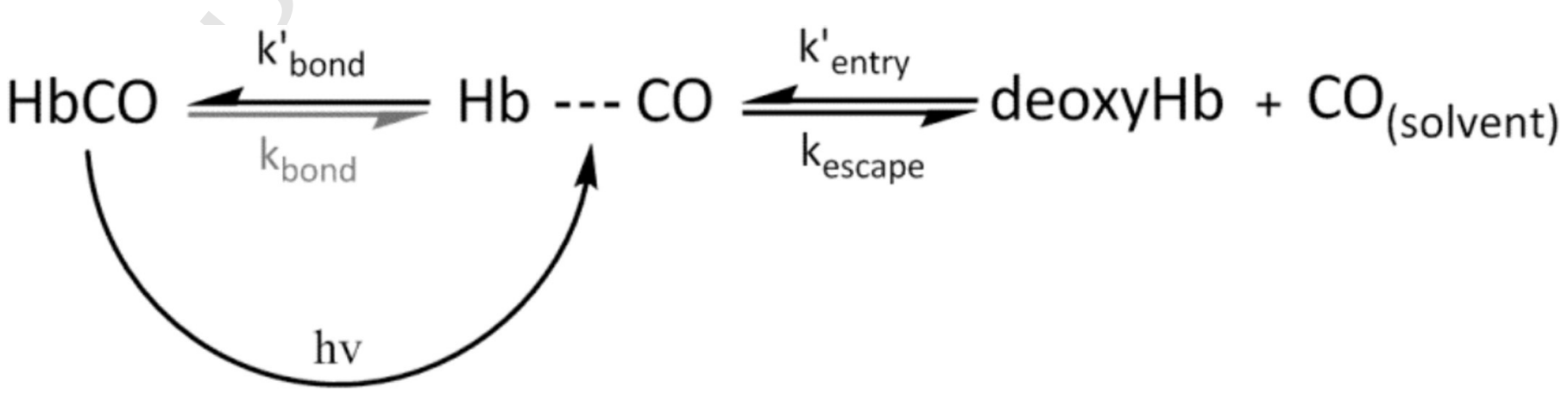



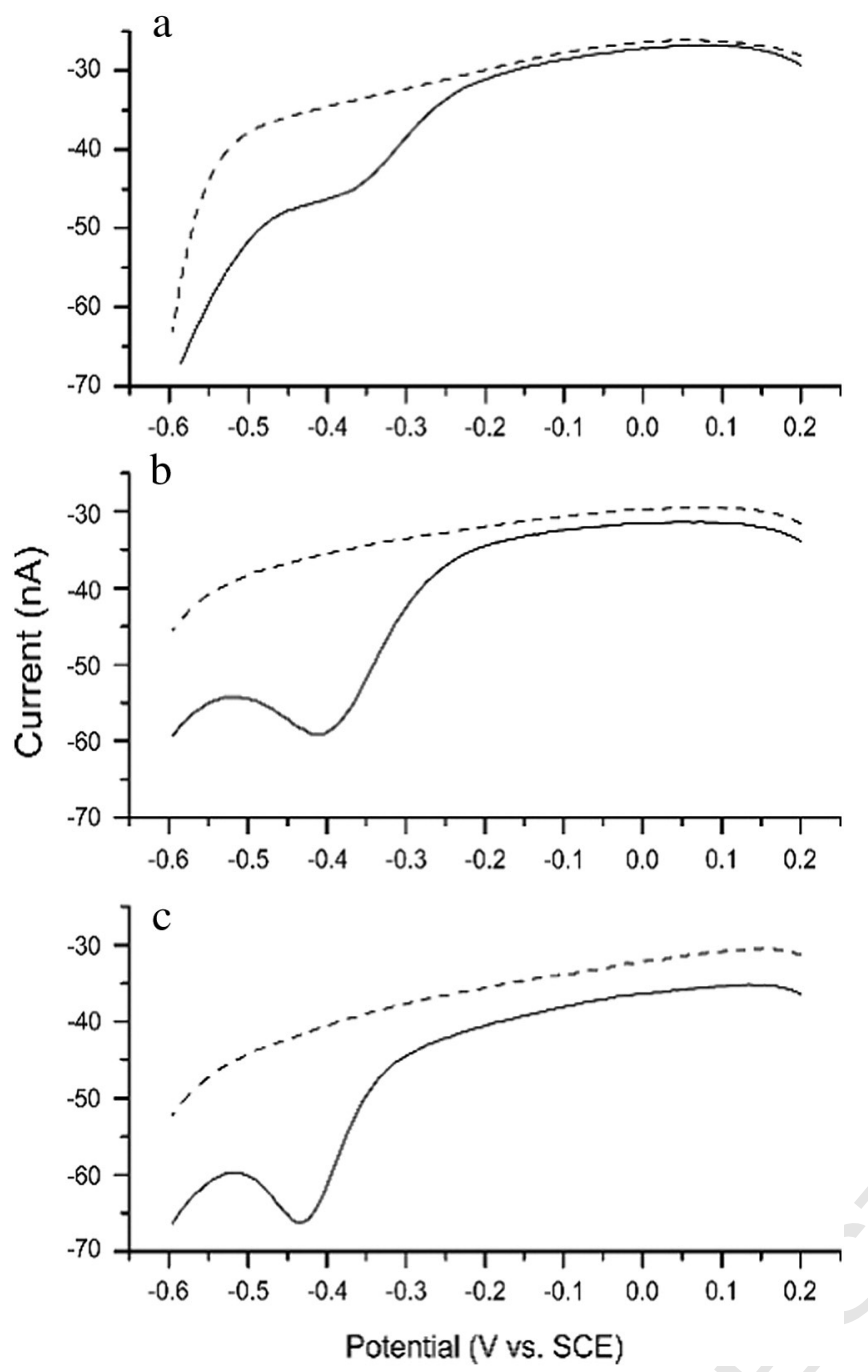

Fig. 9. Differential pulse voltammograms of $A f H b$ (a), AsHbC1D1 (b) and AsHbC1D5 (c). Broken lines show background of the electrodes recorded before placing the proteins. $\mathrm{E}_{\text {modul }}=-25 \mathrm{mV}, \mathrm{E}_{\text {step }}=-5 \mathrm{mV} ; \mathrm{t}_{\text {modul }}=50 \mathrm{~ms}$, $\mathrm{t}_{\text {step }}=0.5 \mathrm{~s}$. Measuring buffer was $10 \mathrm{mM}$ HEPES ( $\mathrm{pH} 7$ ) containing $0.1 \mathrm{M} \mathrm{NaCl}$.

domains $\left(K_{\mathrm{O}_{2}}=0.23 \mu \mathrm{M}^{-1}\right)$ resulting mostly again from a higher dissociation rate constant $\left(k_{\mathrm{O}_{2}}=35.42 \mathrm{~s}^{-1}\right)$. Therefore, the $P_{50}$ value for native $\mathrm{AfHb}$ is significantly higher and thus $\mathrm{O}_{2}$ affinity lower in comparison with the recombinant expressed domains. Nonetheless, the calculated and measured oxygen affinity is moderate and in the range of that of $\mathrm{Mb}$.
When comparing the CO-ligand binding properties of the recombi- 488 nant domains we see differences between themselves as well as with 489 the native $\mathrm{AsHb}$ molecule. Indeed AsHbC1D1 shows monophasic CO 490 binding kinetics, while AsHbC1D5 shows a double exponential relaxa- 491 tion. This points to a heterogeneity of the AsHbC1D5 domain and may 492 point to the existence of two conformations. It is noteworthy that the 493 CO association rate of AsHbC1D1 is 1.3-fold higher than AsHbC1D5 494 (Table 2). Furthermore, from the geminate rebinding, we can conclude 495 that there is a different fraction of geminate recombination for the pro- 496 teins measured (Fig. 8).

Scott et al. studied the effect of point mutations in different positions 498 of SWMb and compared the kinetic values of wild type and mutated 499 proteins [35]. Some mutations in SWMb are in the same position as in 500 AsHbC1D1 or AsHbC1D5 and are listed in Table 4. As an example, in po- 501 sition 65, the residue is Gly in SWMb and Ile in AsHbC1D1. In Table 4, the 502 kinetic values of mutation Gly to Ile in SWMb are compared with that of 503 AsHbC1D1. The comparison of the kinetic values of the recombinant do- 504 mains with $\mathrm{SWMb}$ shows that $K_{\mathrm{O}_{2}}$ and $\mathrm{F}_{\mathrm{gem}}$ of $A s \mathrm{HbC} 1 \mathrm{D} 1$ are more close 505 to the wild type myoglobin than those of AsHbC1D5. Mutation in the 506 second shell of distal residue, such as Val66Gly (smaller residue) in- 507 creases the $F_{\text {gem }}$ from 0.47 to 0.58 which is finally similar to $F_{\text {gem }}$ of 508 AsHbC1D1 (0.57). This also affects the $K_{\mathrm{O}_{2}}$ value and increases it from 509 1.14 to $1.79 \mu \mathrm{M}^{-1}$ while the other mutation in this shell (Thr69Arg) 510 does not vary the $F_{\text {gem. }}$. Moreover, the point mutation Gly65Ile in the 511 wild type SWMb, changes the $K_{\mathrm{O}_{2}}$ of SWMb (from 1.14 to $0.52 \mu \mathrm{M}^{-1}$ ) 512 closer to the $K_{\mathrm{O}_{2}}$ of AsHbC1D5 $\left(0.86 \mu \mathrm{M}^{-1}\right)$ while the $F_{\text {gem }}$ does not 513 change significantly (from 0.47 to 0.49 ). Hence, it shows that the posi- 514 tion 65 may have a significant role in $K_{\mathrm{O}_{2}}$. In other words, changing a 515 small residue to a bigger one decreases the $K_{\mathrm{O}_{2}}$ value by $0.62 \mu \mathrm{M}^{-1}$. 516 The other mutation in the distant place of heme such as Gln8Val mod- 517 ifies the $K_{\mathrm{O}_{2}}$ of SWMb from 1.14 to $0.49 \mu \mathrm{M}^{-1}$ and closer to $K_{\mathrm{O}_{2}}$ of 518 AsHbC1D5 $\left(0.86 \mu \mathrm{M}^{-1}\right)$ (Table 4). It should be considered that as the 519 tertiary structure of the domains is not available, the implementation 520 of the functional and structural relationship may not be totally accurate. 521

Furthermore, as it was mentioned above, the value of $k^{\prime}$ entry is de- 522 fined experimentally as the rate constant for the ligand entry into the 523 $\mathrm{Hb}$. It is calculated as the observed bimolecular rate constant $\left(k_{\mathrm{CO}}^{\prime}\right)$ di- 524 vided by the observed total fraction of the internal rebinding $\left(F_{\text {gem }}\right) 525$ (Eq. (6)). As it was also shown in Table 4, $k^{\prime}$ entry for AsHbC1D1 526 $\left(5.84 \mu \mathrm{M}^{-1} \mathrm{~s}^{-1}\right)$ is 6-times less than the value of SWMb, whereas the 527 value for AsHbC1D5 $\left(69.13 \mathrm{uM}^{-1} \mathrm{~s}^{-1}\right)$ is twice as big as the value of 528 $\mathrm{SWMb}\left(34 \mu \mathrm{M}^{-1} \mathrm{~s}^{-1}\right)$. This means that the two domains show variant 529 ability for the ligand to enter the protein compared to SWMb. The rate 530 of ligand entry in the AsHbC1D5 is higher than that in the SWMb and 531 shows that the ligand can more easily enter the heme pocket of the do- 532 mains. The lower $k^{\prime}$ entry of the native AfHb confirms the closer heme- 533 pocket structure seen using EPR. It must be noted that the values for 534 SWMb are measured based on $\mathrm{O}_{2}$ as the ligand, whereas we have 535 used $\mathrm{CO}$ as ligand.

Table 4

Kinetic values ${ }^{\mathrm{a}}$ of AsHbC1D1 and AsHbC1D5 in comparison with wild type SWMb and its some point mutants based on [35].

\begin{tabular}{|c|c|c|c|c|c|c|c|c|c|c|}
\hline & \multirow{2}{*}{$\frac{k_{\mathrm{O}_{2}}^{\prime}}{\mu \mathrm{M}^{-1} \mathrm{~s}^{-1}}$} & \multirow{2}{*}{$\frac{k_{\mathrm{O}_{2}}}{\mathrm{~s}^{-1}}$} & \multirow{2}{*}{$\frac{K_{\mathrm{O}_{2}}}{\mu \mathrm{M}^{-1}}$} & \multirow{2}{*}{$\frac{k_{\mathrm{gem}}}{\mu s^{-1}}$} & \multirow[t]{2}{*}{$F_{\text {gem }}$} & \multirow{2}{*}{$\frac{k_{\text {bond }}}{\mu s^{-1}}$} & \multirow{2}{*}{$\frac{k_{\text {escape }}}{\mu s^{-1}}$} & \multirow{2}{*}{$\frac{k_{\text {entry }}^{\prime}}{\mu \mathrm{M}^{-1} \mathrm{~s}^{-1}}$} & \multirow[t]{2}{*}{ Common with } & \multirow[t]{2}{*}{ Position of the mutation } \\
\hline & & & & & & & & & & \\
\hline SWMb WT & 16 & 14 & 1.14 & 12.12 & 0.47 & 5.7 & 6.3 & 34 & & \\
\hline AsHbC1D1 & $10.5 \pm 1.6$ & $8.1 \pm 0.8$ & $1.30 \pm 0.18$ & $55 \pm 0.07$ & $0.57 \pm 0.01$ & $31.35 \pm 3$ & $23.65 \pm 4.2$ & $5.82 \pm 0.18$ & & \\
\hline V66G & 25 & 14 & 1.79 & 27.8 & 0.58 & 14 & 9.8 & 43 & AsHbC1D1 & Second Shell of distal Residue \\
\hline T69R & 12 & 11 & 1.08 & 13.3 & 0.47 & 6.3 & 7.0 & 26 & AsHbC1D1 & Second Shell of distal Residue \\
\hline AsHbC1D5 & $13.2 \pm 1.2$ & $15.3 \pm 2.1$ & $0.86 \pm 0.05$ & $61 \pm 0.7$ & $0.23 \pm 0.01$ & $14.03 \pm 0.7$ & $46.97 \pm 1$ & $\begin{array}{l}69.13 \pm 1.6 \\
5.65 \pm 0.05\end{array}$ & & \\
\hline G65I & 17 & 32 & 0.52 & 13.5 & 0.49 & 6.6 & 6.9 & 34 & AsHbC1D5 & Second Shell of distal Residue \\
\hline $\mathrm{I} 99 \mathrm{~V}$ & 18 & 8.8 & 2.1 & 16.1 & 0.74 & 8.8 & 7.3 & 18 & AsHbC1D5 & Proximal side of heme \\
\hline F138A & 24 & 20 & 1.2 & 7.1 & 0.50 & 3.5 & 3.6 & 48 & AsHbC1D5 & Proximal side of heme \\
\hline Q8V & 15 & 30 & 0.49 & 9.1 & 0.41 & 3.7 & 5.4 & 36 & AsHbC1D5 & Distant from heme \\
\hline W14F & 16 & 24 & 0.66 & 9.5 & 0.43 & 3.9 & 5.15 & 36 & AsHbC1D5 & Distant from heme \\
\hline
\end{tabular}

a The kinetic values of the SWMb and its mutants are measured based on $\mathrm{O}_{2}$ as the ligand, whereas those of the recombinant protein are measured based on CO. 


\section{t5.1 Table 5}

The rates of ligand exit from the interior of the protein or $k_{\text {escape }}$ for AsHbC1D1 and AsHbC1D5 are 3.7- and 7.5-folds, respectively, higher than that of SWMb, which indicates that the ligand escapes faster from the inside of the domains than SWMb. To find the possible structural description for this behavior, we considered that ligands in myoglobin, are trapped in a "webbing" pocket of the distal site, and are surrounded by residues $28,29,32,68$, and 107 [35]. The size of this pocket determines the ligand entry equilibrium constant of the protein $\left(K_{\text {entry }}\right)$, which is mathematically defined as $k_{\text {entry }}^{\prime} / k_{\text {escape. }}$. In Table 5 , residues of these certain positions in AsHbC1D1, AsHbC1D5 and reference SWMb, as well as the corresponding values are summarized. As shown in the table, the smaller the residues, the lower the $K_{\text {entry, }}$ hence, less ligand entry into the protein. If we compare the residues, we encounter that the residue in position 68 is the same in all proteins, and the size of residues in positions 28 and 29 in the recombinant proteins (Val and Phe) are almost equal with the size of corresponding residues in SWMb (Ile and Leu). Therefore, the difference in $K_{\text {entry }}$ values is related to the size of the residue in positions 32 and 107. More specifically, in AsHbC1D1 these positions are occupied by smaller residues (Val and Ser, respectively), where the ligand entry constant is the lowest $\left(0.24 \mathrm{M}^{-1}\right)$. In contrast, in SWMb due to the large size of residues in these two positions (Leu and Ile, respectively), the $K_{\text {entry }}$ is the higher $\left(5.39 \mathrm{M}^{-1}\right)$. Moreover, in AsHbC1D5, the size of the residues and the $K_{\text {entry }}$ value $\left(1.47 \mathrm{M}^{-1}\right)$ are moderate. This is in accordance with Scott's proposal [35]. In addition to the size, the nature and orientation of the residues play an important role in the ligand entry and binding to the proteins. To further elucidate this, more structural and mutational analysis is necessary.

As given in Fig. 9 and Table 3, the direct electrochemical measurements reveal variation in the reduction potential $\left(E_{1 / 2}\right)$ of the studied proteins. Interestingly, the reduction potential for $\mathrm{AfHb}$ with 18 globin domains $\left(E_{1 / 2}=-0.13 \mathrm{~V}\right.$ versus SHE) is the highest, whereas the value of AsHbC1D1 $(-0.16 \mathrm{~V})$, existing majorly in tetramer quaternary structure (Fig. 5), lies in between those of $A f \mathrm{Hb}$ and the single domain AsHbC1D5 $(-0.19 \mathrm{~V})$. Thus, the higher number of globin domains stabilizes the iron in the heme in the $\mathrm{Fe}^{2+}$ state, i.e. 18 globin domains stabilize $\mathrm{Fe}^{2+}$ on about $1.5 \mathrm{kcal} / \mathrm{mol}\left(\Delta G_{\mathrm{ET}}=-n F \Delta E\right)$ compared to the single domain. The latter can be important for minimization of methemoglobin $\left(\mathrm{Fe}^{3+}\right)$ formation, which is unable to bind molecular $\mathrm{O}_{2}$.

\section{Conclusion}

To provide explicit answers to the above-mentioned questions, we cloned, expressed and purified two different recombinant globin domains in E. coli and purified the native $\mathrm{Hb}$ from the frozen animal. We utilized electron paramagnetic resonance, laser-flash photolysis and redox chemistry to investigate the physicochemical characteristics of two recombinant globin domains (AsHbC1D1 and AsHbC1D5) and the native one $(A f \mathrm{Hb})$. Particularly, we focused on the comparison of the ligand binding kinetics, heme pocket structure and redox potential. UVvisible spectroscopy and analytical gel filtration of the recombinant proteins indicated single-heme globin-like proteins, which mediate ligand binding. However, there were difficulties in stability of AsHbC1D5 in vitro. Moreover, the gel filtration indicated that there is equilibrium

Ligand entry constant ( $\left.K_{\text {entry}}\right)$ dependency on residue in AsHbC1D1 and AsHbC1D5 in comparison with SWMb based on [35].

\begin{tabular}{|c|c|c|c|c|c|c|c|c|}
\hline & \multicolumn{5}{|c|}{ Positions } & \multirow{2}{*}{$\frac{k_{\text {entry }}^{\prime}}{\mu \mathrm{M}^{-1} \mathrm{~s}^{-1}}$} & \multirow{2}{*}{$\frac{k_{\text {escape }}}{\mu s^{-1}}$} & \multirow{2}{*}{$\frac{K_{\text {entry }}}{\mathrm{M}^{-1}}$} \\
\hline & 28 & 29 & 32 & 68 & 107 & & & \\
\hline AsHbC1D1 & Val & Phe & Val & Val & Ser & $5.82 \pm 0.18$ & $23.65 \pm 4.2$ & 0.24 \\
\hline AsHbC1D5 & Val & Phe & Leu & Val & Val & $\begin{array}{l}69.13 \pm 1.6 \\
5.56 \pm 0.05\end{array}$ & $46.97 \pm 1$ & 1.47 \\
\hline $\mathrm{SWMb}^{\mathrm{a}}$ & Ile & Leu & Leu & Val & Ile & $34 \pm 7$ & $6.3 \pm 1$ & 5.39 \\
\hline
\end{tabular}

a The kinetic values are measured based on $\mathrm{O}_{2}$ as ligand, whereas those of the recombinant protein are measured based on $\mathrm{CO}$. of tetramer and monomeric structure in AsHbC1D1, while the 589 AsHbC1D5 just appears in monomeric structure.

Continuous Wave EPR showed that the heme pocket structure of the 591 $\mathrm{AfHb}$ is more closed than the reference myoglobin. Furthermore, the re- 592 sults of difference pulse voltammetry indicated a difference between 593 the redox potential for recombinants and the native protein, emphasiz- 594 ing that the more the globin domains, the higher the redox potential. $\quad 595$

In order to study the kinetics in more details, we calculated the asso- 596 ciation rate of $\mathrm{CO}$ binding together with geminate rebinding parameters 597 in pseudo first order condition and the association and dissociation of $\mathrm{O}_{2} 598$ in double replacement condition. The results showed that the 599 AsHbC1D1 has monophasic binding to $\mathrm{CO}$, while the $\mathrm{CO}$ association to 600 AsHbC1D1 and AfHb is biphasic. It is also indicated that AsHbC1D1 has 601 a slightly higher oxygen affinity than AsHbC1D5. It shows that they 602 have a diverse role in ligand binding. When studying the full native mol- 603 ecule using ligand binding kinetics, we are faced with a large heteroge- 604 neity due to the presence of at least 18 globin domains. However the 605 overall measurements would support an average oxygen affinity. 606 Taken into account the fact that Artemia live in circumstances of varia- 607 tions in $\mathrm{O}_{2}$ partial pressure due to difference in salinity, we would 608 have expected a larger oxygen affinity. For example, it was reported 609 that Ascaris $\mathrm{Hb}[41,42]$, due to its unique organization of the B10Tyr 610 and E7Gln, has a lower $\mathrm{O}_{2}$ dissociation rate and hence a higher affinity 611 for $\mathrm{O}_{2}$ to support life under low oxygen pressures. Hence, our results 612 demonstrate that the AfHb in contrast to Ascaris $\mathrm{Hb}$ supplies the $\mathrm{O}_{2}$ re- 613 quirement just by increasing the number of the ligand binding domains 614 not by increasing the $\mathrm{O}_{2}$ affinity. Indeed, the affinity is similar to SWMb. 615

\section{Transparency documents}

The Transparency documents associated with this article can be 617 found, in online version.

\section{Acknowledgments}

This work was supported by the Ministry of Science, Research and Q8 Technology of I. R. Iran and by the University of Antwerp.

\section{References}

[1] G. Fermi, M.F. Perutz, B. Shaanan, R. Fourme, The crystal structure of human 623 deoxyhaemoglobin at 1.74 A resolution. J. Mol. Biol. 175 (1984) 159-174.

[2] J.C. Kendrew, R.E. Dickerson, B.E. Strandberg, R.G. Hart, D.R. Davies, D.C. Phillips, V.C. 625 Shore, Structure of myoglobin: a three-dimensional Fourier synthesis at 2 A. resolu- 626 tion, Nature 185 (1960) 422-427.

[3] D. Bashford, C. Chothia A.M. Lesk, Determinants of a protein fold. Unique features of 628 the globin amino acid sequences, J. Mol. Biol. 196 (1987) 199-216.

[4] M. Bolognesi, D. Bordo, M. Rizzi, C. Tarricone, P. Ascenzi, Nonvertebrate hemoglo- 630 bins: structural bases for reactivity, Prog. Biophys. Mol. Biol. 68 (1997) 29-68. 631

[5] S.N. Vinogradov, D. Hoogewijs, X. Bailly, R. Arredondo-Peter, J. Gough, S. Dewilde, L. 632 Moens, J.R. Vanfleteren, A phylogenomic profile of globins, BMC Evol. Biol. 6 (2006) 633 31.

[6] S.N. Vinogradov, D. Hoogewijs, X. Bailly, R. Arredondo-Peter, M. Guertin, J. Gough, S. 635 Dewilde, L. Moens, J.R. Vanfleteren, Three globin lineages belonging to two structur- 636 al classes in genomes from the three kingdoms of life, Proc. Natl. Acad. Sci. U. S. A. 637 102 (2005) 11385-11389.

[7] R.E. Weber, S.N. Vinogradov, Nonvertebrate hemoglobins: functions and molecular 639 adaptations, Physiol. Rev. 81 (2001) 569-628.

8] S.N. Vinogradov, L. Moens, Diversity of globin function: enzymatic, transport, stor- 64 age, and sensing, J. Biol. Chem. 283 (2008) 8773-8777.

[9] K.E. Banister, A.C. Campbell, The Encyclopedia of Aquatic Life, Facts on File, Incorpo- 643 rated, Place Published, 1985.

[10] A.M. Manning, C.N.A. Trotman, W.P. Tate, Evolution of a polymeric globin in the 645 brine shrimp Artemia, Nature 348 (1990) 653-656.

[11] C.N.A. Trotman, A.M. Manning, L. Moens, W.P. Tate, The polymeric hemoglobin mol- 647 ecule of Artemia: interpretation of translated cDNA sequence of nine domains, J. Biol. 648 Chem. 266 (1991) 13789-13795.

[12] C.J. Vandenberg, C.M. Matthews, C.N. Trotman, Variant subunit specificity in the 650 quaternary structure of Artemia hemoglobin, Mol. Biol. Evol. 19 (2002) 1288-1291. 651

[13] C.N. Trotman, A.M. Manning, J.A. Bray, A.M. Jellie, L. Moens, W.P. Tate, Interdomain 652 linkage in the polymeric hemoglobin molecule of Artemia, J. Mol. Evol. 38 (1994) 653 628-636.

[14] C.M. Matthews, C.J. Vandenberg, C.N. Trotman, Variable substitution rates of the 18655 domain sequences in Artemia hemoglobin, J. Mol. Evol. 46 (1998) 729-733. 
[15] D.T. Chyou, V.L. Rawle, C.N. Trotman, Quaternary structure of Artemia haemoglobin II: analysis of $\mathrm{T}$ and $\mathrm{C}$ polymer alignment and interpolymer interface, BMC Struct. Biol. 7 (2007) 26-40.

[16] G. Wolf, M. Van Pachtenbeke, L. Moens, M.L. Van Hauwaert, Oxygen binding characteristics of Artemia hemoglobin domains, Comp. Biochem. Physiol. B: Comp. Biochem. 76 (1983) 731-736.

[17] J. D'Hondt, L. Moens, J. Heip, A. D'Hondt, M. Kondo, Oxygen-binding characteristics of three extracellular haemoglobins of Artemia salina, Biochem. J. 171 (1978) 705-710.

[18] J. Heip, L. Moens, M. Joniau, M. Kondo, Ontogenetical studies on extracellular hemoglobins of Artemia salina, Dev. Biol. 64 (1978) 73-81.

[19] J. Heip, L. Moens, M. Kondo, Effect of concentrations of salt and oxygen on the synthesis of extracellular hemoglobins during development of Artemia salina, Dev. Biol. 63 (1978) 247-251.

[20] V. Sugumar, N. Munuswamy, Physical, biochemical and functional characterization of haemoglobin from three strains of Artemia, Comp. Biochem. Physiol. A Mol. Integr. Physiol. 146 (2007) 291-298.

[21] D. Geelen, L. Moens, J. Heip, R. Hertsens, K. Donceel, J. Clauwaert, The structure of Artemia sp. haemoglobins-I. Isolation and characterization of oxygen binding domains obtained by limited tryptic digestion, Int. J. Biochem. 14 (1982) 991-1001.

[22] L. Moens, D. Geelen, M.L. Van Hauwaert, G. Wolf, R. Blust, R. Witters, R. Lontie, The structure of Artemia sp. haemoglobin. Cleavage of the native molecules into functional units by limited subtilisin digestion, Biochem. J. 223 (1984) 861-869.

[23] L. Moens, M. Kondo, Evidence for a dimeric form of Artemia salina extracellular hemoglobins with high-molecular-weight subunits, Eur. J. Biochem. 82 (1978) 65-72.

[24] D. Hoogewijs, E. Geuens, S. Dewilde, L. Moens, A. Vierstraete, S. Vinogradov, J. Vanfleteren, Genome-wide analysis of the globin gene family of $C$. elegans, IUBMB Life 56 (2004) 697-702.

[25] S. Dewilde, K. Mees, L. Kiger, C. Lechauve, M.C. Marden, A. Pesce, M. Bolognesi, L. Moens, Expression, purification, and crystallization of neuro- and cytoglobin, Methods Enzymol. 436 (2008) 341-357.

[26] S. Helbo, S. Dewilde, D.R. Williams, H. Berghmans, M. Berenbrink, A.R. Cossins, A. Fago, Functional differentiation of myoglobin isoforms in hypoxia-tolerant carp indicates tissue-specific protective roles, Am. J. Physiol. Regul. Integr. Comp. Physiol. 302 (2012) R693-R701.

[27] R.E. Weber, A. Fago, A.L. Val, A. Bang, M.L. Van Hauwaert, S. Dewilde, F. Zal, L. Moens, Isohemoglobin differentiation in the bimodal-breathing amazon catfish Hoplosternum littorale, J. Biol. Chem. 275 (2000) 17297-17305.

[28] J. Uzan, S. Dewilde, T. Burmester, T. Hankeln, L. Moens, D. Hamdane, M.C. Marden, L. Kiger, Neuroglobin and other hexacoordinated hemoglobins show a weak temperature dependence of oxygen binding, Biophys. J. 87 (2004) 1196-1204.

[29] S. Dewilde, A.I. Ioanitescu, L. Kiger, K. Gilany, M.C. Marden, S. Van Doorslaer, J. Vercruysse, A. Pesce, M. Nardini, M. Bolognesi, L. Moens, The hemoglobins of the trematodes Fasciola hepatica and Paramphistomum epiclitum: a molecular biological, physico-chemical, kinetic, and vaccination study, Protein Sci. Publ. Protein Soc. 17700 (2008) 1653-1662.

[30] I. Birukou, R.L. Schweers, J.S. Olson, Distal histidine stabilizes bound $\mathrm{O}_{2}$ and acts as a 702 gate for ligand entry in both subunits of adult human hemoglobin, J. Biol. Chem. 285703 (2010) 8840-8854. 704

[31] J.S. Olson, E.W. Foley, D.H. Maillett, E.V. Paster, Measurement of rate constants 705 for reactions of $\mathrm{O}_{2}, \mathrm{CO}$, and NO with hemoglobin, Methods Mol. Med. 82 (2003) 706 65-91.

[32] J. Haladjian, P. Bianco, F. Nunzi, M. Bruschi, A permselective-membrane electrode for 708 the electrochemical study of redox proteins. Application to cytochrome c552 from 709 Thiobacillus ferrooxidans, Anal. Chim. Acta 289 (1994) 15-20. 710

[33] É. Lojou, P. Bianco, Membrane electrodes can modulate the electrochemical re- 711 sponse of redox proteins - direct electrochemistry of cytochrome c, J. Electroanal. 712 Chem. 485 (2000) 71-80. 713

[34] C.P. Scholes, K.M. Falkowski, S. Chen, J. Bank, Electron nuclear double resonance 714 (ENDOR) of bis(imidazole) ligated low-spin ferric heme systems, J. Am. Chem. 715 Soc. 108 (1986) 1660-1671. 716

[35] E.E. Scott, Q.H. Gibson, J.S. Olson, Mapping the pathways for $\mathrm{O}_{2}$ entry into and exit 717 from myoglobin, J. Biol. Chem. 276 (2001) 5177-5188. 718

[36] R.E. Cashon, M.E. Vayda, B.D. Sidell, Kinetic characterization of myoglobins from ver- 719 tebrates with vastly different body temperatures, Comp. Biochem. Physiol. B 720 Biochem. Mol. Biol. 117 (1997) 613-620.

[37] E. Antonini, M. Brunori, Hemoglobin and Myoglobin in Their Reactions With Li- 722 gands, North-Holland Pub. Co, 1971. (Place Published). 723

[38] A. Pesce, M. Nardini, S. Dewilde, L. Capece, M.A. Marti, S. Congia, M.D. Salter, G.C. 724 Blouin, D.A. Estrin, P. Ascenzi, L. Moens, M. Bolognesi, J.S. Olson, Ligand migration 725 in the apolar tunnel of Cerebratulus lacteus mini-hemoglobin, J. Biol. Chem. 286726 (2011) 5347-5358.

39] G. Amiconi, E Antonini, M. Brunori, H. Formaneck, R. Huber Functional properties of 728 native and reconstituted hemoglobins from Chironomus thummi thummi, Eur. J. 729 Biochem. FEBS 31 (1972) 52-58.

40] M.D. Salter, K. Nienhaus, G.U. Nienhaus, S. Dewilde, L. Moens, A. Pesce, M. Nardini, 731 M. Bolognesi, J.S. Olson, The apolar channel in Cerebratulus lacteus hemoglobin is 732 the route for $\mathrm{O}_{2}$ entry and exit, J. Biol. Chem. 283 (2008) 35689-35702. 733

[41] A. Pesce, S. Dewilde, L. Kiger, M. Milani, P. Ascenzi, M.C. Marden, M.L. Van Hauwaert, 734 J. Vanfleteren, L. Moens, M. Bolognesi, Very high resolution structure of a trematode 735 hemoglobin displaying a TyrB10-TyrE7 heme distal residue pair and high oxygen 736 affinity, J. Mol. Biol. 309 (2001) 1153-1164.

42] E.S. Peterson, S. Huang, J. Wang, L.M. Miller, G. Vidugiris, A.P. Kloek, D.E. Goldberg 738 M.R. Chance, J.B. Wittenberg, J.M. Friedman, A comparison of functional and struc- 739 tural consequences of the tyrosine B10 and glutamine E7 motifs in two invertebrate 740 hemoglobins (Ascaris suum and Lucina pectinata), Biochemistry 36 (1997) 741 13110-13121. 